\title{
Does Current Nephrology Fellowship Training Affect Utilization of Peritoneal Dialysis in the United States?
}

\author{
Nand K. Wadhwa ${ }^{1}$, Catherine R. Messina ${ }^{2}$, Nasser M. Hebah ${ }^{3}$ \\ ${ }^{1}$ Division of Nephrology, Stony Brook School of Medicine, Stony Brook, New York, USA \\ ${ }^{2}$ Department of Preventive Medicine, Stony Brook School of Medicine, Stony Brook, New York, USA \\ ${ }^{3}$ Corporate Home Dialysis, Dialysis Clinic Inc., Nashville, USA. \\ Email: nand.wadhwa@stonybrookmedicine.edu
}

Received April 2, 2013; revised May 13, 2013; accepted May 26, 2013

Copyright (c) 2013 Nand K. Wadhwa et al. This is an open access article distributed under the Creative Commons Attribution License, which permits unrestricted use, distribution, and reproduction in any medium, provided the original work is properly cited.

\begin{abstract}
Background: The 2010 US Renal Data System annual report revealed that peritoneal dialysis is used by only 7\% of end-stage renal disease patients on chronic dialysis vs. hemodialysis which is used by $93 \%$ of such patients, despite documented benefits of peritoneal dialysis over hemodialysis in these cases. Purpose: We examined whether education of nephrology fellows contributed to underutilization of peritoneal dialysis in the US. Methods: Self-report questionnaires were administered electronically to nephrology fellowship training program directors, October 2010-March 2011 (55\% response). Results: Median number of training faculty and patients/fellow were significantly lower for peritoneal-dialysis vs. hemodialysis training. Hours of didactic teaching for fellows over their 2-year training period were significantly lower for peritoneal dialysis vs. hemodialysis. Peritoneal dialysis training was $20 \%$ of total training vs. $80 \%$ for hemodialysis. Most program directors (87\%) believed lack of trained faculty in peritoneal dialysis and insufficient peritoneal dialysis patient population contributed to inadequate fellows' peritoneal dialysis training. Conclusions: Findings suggest that current nephrology fellowship training in peritoneal dialysis is inadequate and contributes to its underutilization.
\end{abstract}

Keywords: Peritoneal Dialysis; Hemodialysis; Utilization; Nephrology Fellowship Training

\section{Introduction}

Renal replacement therapy for patients with end-stage renal disease (ESRD) includes kidney transplantation and chronic dialysis. Most ESRD patients are treated with in-center hemodialysis (HD) and home peritoneal dialysis (PD) for prolonged periods because of limited availability of organ donors for kidney transplantation. As of December 31, 2010, among chronic dialysis patients, approximately 383,992 (93\%) patients were receiving HD while 29,733 (7\%) were on PD [1]. The incident HD population reached 103,874 patients in 2010. New PD patients peaked at 9408 in 1995, and have since fallen to 7586 [1]. This decline continues despite the cost effectiveness of PD therapy as compared to in-center HD, improving patient outcomes, advances in PD therapy including a decrease in peritonitis rate, new solutions such as icodextrin and the new generation of automated cycling machines allowing appropriate dialysis clear-

*Authors and Affiliations: The authors do not have any conflicts of interest or financial relationships to disclose. ances [1-5]. PD underutilization has occurred despite the fact that nephrologists in the United States report that about 35\% of ESRD patients should be maintained on PD therapy [6]. Not only are PD and HD associated with similar survival in incident dialysis patients starting therapy electively as outpatients [7], but also PD offers survival benefits in almost $67 \%$ of incident ESRD patients who are non-diabetics and younger diabetics with no additional comorbidity [8].

PD underutilization is related in part to inadequate training of nephrologists in PD [9]. A recent (2010) survey of self-perceived competency among US nephrologists after completion of nephrology fellowship training revealed that only $56 \%$ felt well trained and competent in the care of chronic PD patients vs. $80 \%$ who felt well trained and competent in the care of chronic in-center HD patients-although 92\% ranked care of chronic PD patients as an area that is "somewhat or very important" [10]. Related to nephrologist concerns about lack of competence or comfort with $\mathrm{PD}$, is inadequate exposure to PD patients during their training. Although US neph- 
rologists spent $>35 \%$ of their time providing care for ESRD patients [11], Mehrotra et al. [12] reported a decnade ago that $29 \%$ of fellows in US training programs were exposed to $<5$ PD patients and $14 \%$ of these fellows spent $<5 \%$ of their training time caring for PD patients.

Lack of exposure to PD during training influences nephrologist's referral patterns (i.e., preferences for treatment modality) throughout their career and may influence patients' treatment choice [13] and therefore affect patient outcomes. While some have suggested that choice of dialysis modality selection is driven by patient preference [14,15]. Wuerth et al. reported that $83 \%$ of interviewed patients indicated that their physician influenced their ESRD treatment choice [16]. Of note is Stack's finding that patients who were autonomous in the ESRD treatment decision-making process were more likely to receive PD rather than HD compared to patients whose medical team were more actively involved in treatment modality decision making [17].

In 2002, Mehrotra et al. [12] described the status of dialysis training in the US in terms of the availability of resources and allocation of time for training fellows. We undertook this study to update Mehrotra et al.'s 2002 [12] observations and examine the current status of nephrology fellowship training in hemodialysis and peritoneal dialysis in the US.

\section{Materials and Methods}

The project protocol was approved by the Stony Brook University institutional review board. Self-report questionnaires were administered electronically via Survey Monkey, during October 2010-March 2011, to US Nephrology fellowship program directors. The names and email addresses of all US adult Nephrology fellowship program directors were obtained from the American Society of Nephrology listserv (directors of pediatric nephrology programs were excluded). Questionnaire responses were obtained anonymously. Questionnaires were re-administered to Program Directors approximately 4 weeks after the initial administration to encourage replies from those who had not already done so. This was repeated two more times. No incentives were offered.

The questionnaire was developed by the first author and reviewed by the second and third authors. Questionnaire items obtained information on training program characteristics (e.g., number of clinical nephrology faculty; number of nephrology fellows) and training activities relating to HD and PD (e.g., number of adult patients on HD and PD; percent of fellows time managing HD and PD; didactic lectures in HD and PD; type of training (block rotation or continuity care) and estimate of time spent on HD and PD; etc). Program directors described their perceptions of the adequacy of PD training at their institution and in the US, and noted barriers to the utilization of PD in the US The questionnaire took approximately 15 minutes to complete, and was pretested on a small group of physicians prior to distribution.

Study data were downloaded from Survey Monkey directly into an SPSS-formatted file and the statistical program SPSS (IBM SPSS, version 19) was used for all data analyses. Descriptive statistics (frequencies, proportions, medians, and ranges) are provided for all study data. The Wilcoxon signed rank test was used for comparisons of median values.

\section{Results}

\subsection{Response Rate and Distribution of Respondent Training Programs}

Questionnaires were administered to directors of 143 nephrology fellowship programs. Directors of 78 programs completed the questionnaires to yield an overall response rate of $54.5 \%$. Our response rate is comparable to the response rate of $47.3 \%$ attained by a prior survey of members of the National Kidney Foundation regarding opinions and attitudes about dialysis modality selection conducted in 1997 [6]. Response rates varied by US Census Region [18]: 45\% $(\mathrm{n}=35)$ of responding US Program directors were located in the northeast; $13 \%(n=10)$ were located in the west; $26 \%(n=20)$ were located in the south; and $17 \%(n=13)$ were in the mid-west [NOTE: denominator $=78$ responding program directors]. When examined by the regional location of nephrology programs listed on the American Society of Nephrology listserv (i.e., denominator represents total programs in the specific region): $69 \%(n=35)$ of programs located in the northeast, $55 \%(\mathrm{n}=10)$ of those located in the west; $48 \%(n=20)$ of those located in the south; and $42 \%(n=13)$ of those located in the mid-west, were represented.

\subsection{Training Resources and Program Characteristics}

Self-reported HD and PD training resources are presented in Table 1. The median faculty/fellow ratio was significantly lower for PD compared to HD as was the median patients / fellow ratio (all p's $<0.001$ ).

$94 \%(n=67 / 71)$ and $93 \%(n=66 / 71)$ of program directors indicated that their fellows receive didactic teaching lectures during their tenure in HD and/or PD, respectively. However, the median number of teaching lecture hours reported was significantly lower for PD (6 hours ( 2 - 30 hours)) compared to HD (10 hours (range = 2 - 30 hours)), $\mathrm{p}<0.001$ [data not shown].

$98.7 \%$ of the responding program directors $(n=77 / 78)$ 
Table 1. Program director $(n=78$ respondents) reports of hemodialysis and peritoneal dialysis training resources for nephrology fellows.

\begin{tabular}{cccc}
\hline Training resource & Total & Hemodialysis (median, range) & Peritoneal dialysis (median, range) \\
\hline Number of full and/or part time faculty & $11(1-28)$ & $6(0-24)$ & $1(0-14)$ \\
Faculty/fellow ratio & $1.8(0.1-5.0)$ & $1.2^{*}(0.3-4.0)$ & $0.5^{*}(0.1-2.5)$ \\
Number of adult patients on HD and PD & & $200(40-700)$ & $30(1-20)$ \\
Patients/fellow ratio & & $37.5^{*}(5.5-200)$ & $5.0^{*}(0.2-17.1)$ \\
\hline
\end{tabular}

${ }_{\mathrm{p}}^{*}<0.001$ for Hemodialysis vs. Peritoneal dialysis comparison; Wilcoxon Signed Ranks Test.

provide chronic dialysis training for their fellows. With regard to training characteristics of their outpatient chronic dialysis programs, 38\% $(n=29 / 77)$ of responding program directors indicated that they only provide continuity care; $29 \%(n=22 / 77)$ responded that they only provide block of time rotation; and 34\% $(n=26 / 77)$ indicated that they provide both continuity care and block of time rotation [data not shown]. As shown in Table 2, among programs providing continuity care or block rotation and continuity care, the smaller proportion assigning dialysis patients to fellows were for PD rather than HD. Similarly, the smaller proportion of total dialysis training time among programs offering block rotation, continuity care, or both was devoted to PD rather than HD.

\subsection{Perceived Adequacy of PD Training in the US}

87\% ( $n=60 / 75)$ of responding program directors believe that PD training in the US is inadequate. When asked to describe the reason for this belief, the primary reasons noted by these program directors included: insufficient numbers of PD patients/lack of exposure to PD patients (71\%); and lack of available training in $\mathrm{PD} /$ faculty not comfortable with PD (20\%) [data not shown].

\subsection{Estimations of Adequate PD Training}

Figures 1(a) and (b) present program directors estimations of what is needed for adequate PD training. Overall, $76 \%$ ( $n=52 / 68$ ) of program directors felt that $>5 \%$ of total training time is adequate for PD training. Of these, the most frequent percent total training time noted was $5 \%$ - 10\% (35\%; 24/68) followed by 10\% - 20\% (25\%; $17 / 68)$. In general, $81 \%(n=56 / 69)$ of program directors felt that assigning $>5$ chronic PD patients/fellow is adequate for PD training over the fellows' two year training period. The most frequently cited number of chronic PD patients/fellow was 5 - 10 (52\%; 36/69). Among those program directors who felt that assigning $>5$ chronic PD patients/fellow is adequate for PD training over the fellows' two year training period, approximately 50\% (n = 29/56) indicated having 30 or more patients on PD within their programs, with patient/fellow ratios ranging from 6.00 to 17.00 (data not shown).

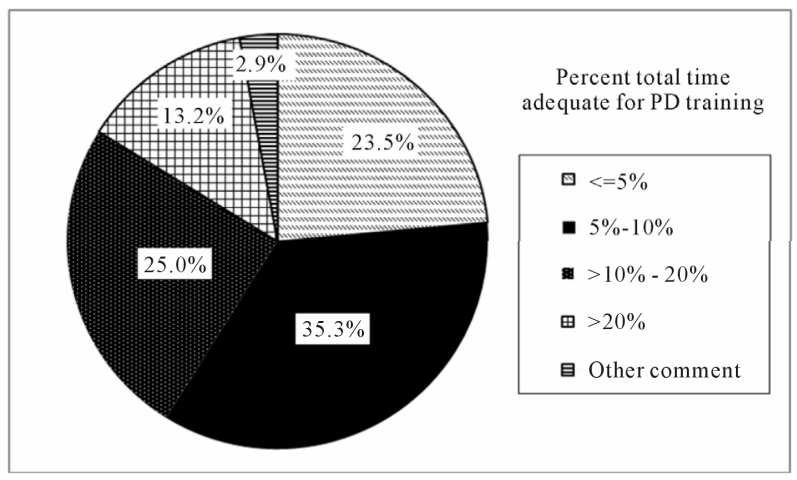

(a)

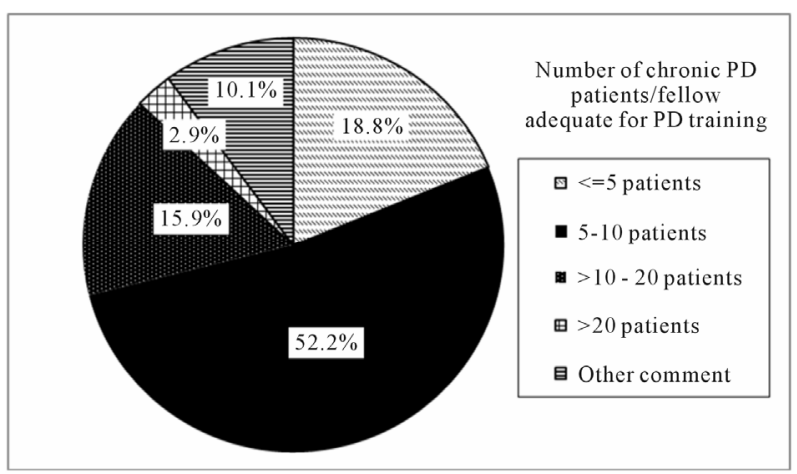

(b)

Figure 1. Percent total training time and number of patients/fellow program directors believe is adequate for $P D$ training. (a) Percent total training time program directors believe is adequate for PD training. Note: \%'s represent the proportion of responding program directors indicating a specific amount for training time. Other comments = "hard to quantify what proportion of time translates into competency", etc.; (b) Number of patients/fellow program directors believe is adequate for PD training. Note: \%'s represent the proportion of responding program directors indicating a specific number of patients. Other comments = "not a set number"; "exposure to complications more important”, etc.

\subsection{Factors Which Limit Utilization of PD in the US}

As seen in Table 3, program directors most often cited limited physician training in PD (88\%) as a physician/ nurse related factor which limits utilization of PD in the US Greater than $50 \%$ of respondents also cited poor 
Table 2. Program directors' estimates of training in hemodiaysis and peritoneal dialysis (n = 77 respondents).

\begin{tabular}{|c|c|c|c|c|c|}
\hline & Block rotation & Continuity care & \multicolumn{3}{|c|}{ Block rotation and continuity care } \\
\hline & $\begin{array}{l}\% \text { (n) of programs where } \\
\text { fellows are assigned } \\
\text { dialysis patients }\end{array}$ & $\begin{array}{l}\% \text { of training during } \\
2 \text { years tenure } \\
\text { (median (range)) }\end{array}$ & $\begin{array}{l}\% \text { (n) of programs where } \\
\text { fellows are assigned } \\
\text { dialysis patients }\end{array}$ & $\begin{array}{l}\% \text { (n) of programs where } \\
\text { fellows are assigned } \\
\text { dialysis patients }\end{array}$ & $\begin{array}{c}\% \text { of training during } \\
2 \text { years tenure } \\
\text { (median (range)) }\end{array}$ \\
\hline Hemodialysis & 0 & $80(34-95)$ & $27.6(8)$ & $26.9(7)$ & $80(0-100)$ \\
\hline Peritoneal dialysis & $5(1)$ & $20(5-66)$ & $10.3(3)$ & $7.7(2)$ & $20(0-100)$ \\
\hline Both & 95 (21) & --- & $62.1(18)$ & 65.4 (17) & ---- \\
\hline
\end{tabular}

Table 3. Program director beliefs regarding factors which limit utilization of peritoneal dialysis therapy in the US $(n=$ 69 respondents).

\begin{tabular}{|c|c|}
\hline \multirow{2}{*}{$\begin{array}{c}\text { Factors which can potentially limit } \\
\text { utilization of PD }\end{array}$} & $\begin{array}{c}\text { Program directors of } \\
\text { dialysis training }\end{array}$ \\
\hline & \% respondents ${ }^{*}(\mathrm{n})$ \\
\hline \multicolumn{2}{|l|}{ Physician/nurse related factors: } \\
\hline Limited physician training in PD & $88.4(61)$ \\
\hline Poor personal experience with PD & $59.4(41)$ \\
\hline Problems with hospital support for PD & $53.6(37)$ \\
\hline $\begin{array}{l}\text { Lack of nursing expertise to support PD } \\
\text { program }\end{array}$ & $49.3(34)$ \\
\hline Lower physician reimbursement for PD & $20.3(14)$ \\
\hline None of these are barriers & $13.0(9)$ \\
\hline \multicolumn{2}{|l|}{ Dialysis provider related factors: } \\
\hline $\begin{array}{l}\text { Lack of PD experienced and dedicated } \\
\text { management }\end{array}$ & $75.4(52)$ \\
\hline $\begin{array}{l}\text { Lack of PD infrastructure, dedicated } \\
\text { resources, and support }\end{array}$ & $66.7(46)$ \\
\hline Proliferation of in-center HD units & $55.1(38)$ \\
\hline None of these are barriers & $7.2(5)$ \\
\hline \multicolumn{2}{|l|}{ Patient related factors: } \\
\hline Lack of patient education on PD & $78.3(54)$ \\
\hline Other patient related barrier & $20.03(14)$ \\
\hline Patient education is not a barrier & $17.4(12)$ \\
\hline \multicolumn{2}{|l|}{ Therapy related factors: } \\
\hline $\begin{array}{l}\text { Concerns about PD clinical outcomes } \\
\text { (relative to HD outcomes) }\end{array}$ & $43.5(30)$ \\
\hline $\begin{array}{l}\text { Concerns about relative mortality rates } \\
\text { with PD }\end{array}$ & $31.9(22)$ \\
\hline None of these are barriers & $49.3(34)$ \\
\hline
\end{tabular}

*Respondents could indicate more than one factor.

personal experience with PD and approximately 50\% cited problems with hospital and nursing support as limiting factors.

With regard to dialysis provider related factors, lack of
PD experience and dedicated management was cited most often (75\%) followed by lack of PD infrastructure, dedicated resources, and support (67\%) and proliferation of in-center HD units (55\%). Among the patient related factors limiting utilization of PD, 78\% of program directors cited lack of patient education on PD. However, less than half of program directors (43\%) cited concerns about PD clinical outcomes (relative to HD outcomes) as a therapy related factor limiting utilization of PD.

\section{Discussion}

Mehrota et al.'s 2002 national survey of nephrology training program directors described disparities in resources available for PD vs. HD training [12]. Approximately 10 years later, we found that the large majority of responding Program Directors in our national sample still believe that PD training in the US is inadequate. The primary reasons given relate to inadequacy of training in PD and include insufficient numbers of PD patients for adequate exposure to PD, and faculty who are not comfortable with PD. These findings are also consistent with another prior study which found that only $56 \%$ of nephrologists felt well trained and competent in the care of chronic PD patients while approximately $80 \%$ of respondents reported that they were well trained and felt competent after leaving fellowship in the care of chronic HD patients [10]. Level of physician perceived comfort and competence in the care of PD patients impacts both provider and patient decisions about choice of therapy [13] and consequently influences the rate of utilization of PD.

Related to adequacy of training, our survey of program directors suggest that the availability of training resources (faculty and patients) and allocation of didactic and training time for fellows in providing care to ESRD patients receiving dialysis are significantly lower for PD than HD in the US. The main limiting factors indicated by program directors were insufficiently trained faculty in PD and/or insufficient PD patient population to ensure appropriate training for fellows in providing care for patients undergoing PD. In addition, our findings suggest that the availability of training resources for PD has de- 
clined in the US since Mehrotra et al. reported on this in 2002 [12]. We found that median number of full/parttime faculty members were significantly lower for PD than for HD. Faculty numbers for PD have dropped from a median of 4 reported 10 years ago [12], to a median of 1 noted in our recent survey. Similarly, the median faculty/fellow ratio for PD training decreased from 1 [12] to 0.5 , as evidenced by our data. The patients/fellow ratio has declined from a median of 6.7 [12], to 5.0 (our data). In contrast, we found that median numbers of faculty members, faculty/fellow ratio and patients/fellow ratio for HD training have remained similar to those noted 10 years earlier by Mehrotra et al. [12]. We found that among programs providing continuity care or block rotation and continuity care (continuity care is the preferred experience [19]), the smaller proportion assigned dialysis patients to fellows for PD rather than HD. Similarly, the smaller proportion of total dialysis training time among programs offering block rotation, continuity care, or both was devoted to PD rather than HD. This has not changed in comparison to the previous report [12].

A decline in the number of ESRD patients on PD has worsened this resource for nephrology fellowship training. Responding program directors most often cited limited physician training in PD as a physician/nurse related factor which limits utilization of PD in the US and greater than half also cited poor personal experience with PD. This sets up an adverse cycle since new ESRD patients' treatment choices are often influenced by their physicians $[13,16]$. We found that among patient related factors limiting utilization of PD, the majority of program directors cited lack of patient education on PD compared to less than half who cited concerns about PD clinical outcomes (relative to HD outcomes) as a therapy related factor limiting utilization of PD. Our data suggest that program directors perceive training and education as greater impediments to utilization of PD, than clinical factors.

What is needed for adequate PD training is debatable. $76 \%$ of program directors felt that allocating $>5 \%$ of total training time is adequate for PD training and in general, 81\% felt that assigning $>5$ chronic PD patients/fellow was also adequate for PD training over the fellows' two year training period). This may reflect program directors' beliefs that these are the number of patients needed for a fellow to attain competency. However, our questionnaire did not explicitly address the competency of PD training. Future surveys should specifically ask about training resources and experiences needed to attain competency in this area and should focus on evaluating and achieving competency in PD among fellows [20].

Study limitations include the response rate of $55 \%$. However, given the voluntary nature of the survey, this response rate is comparable to that achieved in the other studies [6,12]. Furthermore, response rates varied re- gionally with representation greatest in the northeast. There is some evidence that the likelihood of PD placement is greatest in the northeast [17], although others have found that PD use did not differ in urban vs. rural settings [21], it is not surprising that directors of nephrology fellowship programs located in the northeast might more frequently to respond to a survey about PD utilization. Nonetheless, despite the over-representation of programs located in areas of highest PD use, our findings still suggest underutilization of PD related to inadequate training in PD.

Another limitation relates to the accuracy of self-report data obtained from this present survey, particularly descriptions of the distribution of time spent by fellows on PD vs. HD activities. This was estimated by responding program directors and not based on actual documentation of individual fellows' time. Nonetheless, we believe that their estimates of training practices and activities are adequate and reliable because most program directors are closely involved in outlining or designing the structure of dialysis training. In addition, estimates of time spent by fellows on PD vs. HD activities given by our responding program directors were similar to estimates provided by nephrology training program fellows in a prior study [19].

In conclusion, our survey of the program directors supports the contention that current nephrology fellowship training in $\mathrm{PD}$ in the US remains inadequate, despite documented advantages of PD over HD for treatment of ESRD among chronic dialysis patients. The adequacy of PD training resources needs appraisal by the nephrology community and competency in PD training needs to be defined and evaluated [19,20]. Minimum standards of PD training for each nephrology fellow should to be established similar to that of nephrology transplant training as mandated by the American College of Graduate Medical Education. Targeting current faculty for PD-directed educational efforts can also do much to enhance PD utilization and improve ESRD patient outcomes. Current faculty involved in training programs need to be trained or retrained in PD so that they feel comfortable in training fellows in $\mathrm{PD}$ and providing care to $\mathrm{PD}$ patients.

\section{Acknowledgements}

This project was supported by a grant from Dialysis Clinics Inc., to Nand Wadhwa MD, FACP, FRCP. The sponsor did not have a role in any of the following: study design; collection, analysis, and interpretation of data; writing this report; and the decision to submit this report for publication

\section{REFERENCES}

[1] US Renal Data System, “USRDS 2012 Annual Data Re- 
port," Department of Health and Human Services, National Institutes of Health, Bethesda, 2012.

[2] P. K. Li, C. C. Szeto, B. Piraino, et al., "Peritoneal Dialysis-Related Infections Recommendations: 2010 Update,” Peritoneal Dialysis International, Vol. 30, No. 4, 2010, pp. 393-423. doi:10.3747/pdi.2010.00049

[3] J. E. Frampton and G. L. Plosker, "Icodextrin: A Review of Its Use in Peritoneal Dialysis,” Drugs, Vol. 63, No. 19, 2003, pp. 2079-2105. doi:10.2165/00003495-200363190-00011

[4] P. H. Juergensen, A. L. Murphy, K. A. Pherson, A. S. Kliger and F. O. Finkelstein, "Tidal Peritoneal Dialysis: Comparison of Different Tidal Regimens and Automated Peritoneal Dialysis,” Kidney International, Vol. 57, 2001, pp. 2603-2607. doi:10.1046/j.1523-1755.2000.00120.x

[5] R. Mehrotra, D. Kermah, L. Fried, et al., "Chronic Peritoneal Dialysis in the United States: Declining Utilization Despite Improving Outcomes," Journal of the American Society of Nephrology, Vol. 18, No. 10, 2007, pp. 27812788. doi:10.1681/ASN.2006101130

[6] D. C. Mendelssohn, S. R. Mullaney, B. Jung, P. G. Blake and R. L. Mehta, "What Do American Nephrologists Think about Dialysis Modality Selection?" American Journal of Kidney Diseases, Vol. 37, No. 1, 2001, pp. 2229.

[7] R. R. Quinn, J. E. Hux, M. J. Oliver, P. C. Austin, M. Tonelli and A. Laupacis, "Selection Bias Explains Apparent Differential Mortality between Dialysis Modalities," Journal of the American Society of Nephrology, Vol. 22, No. 8, 2011, pp. 1534-1542. doi:10.1681/ASN.2010121232

[8] R. Mehrotra, Y. Chiu, Kalantar-Zadeh, J. Bargman and E. Vonesh, "Similar Outcome with Hemodialysis and Peritoneal Dialysis in Patients with End-Stage Renal Disease," Archives of Internal Medicine, Vol. 171, No. 2, 2007, pp. 110-118. doi:10.1001/archinternmed.2010.352

[9] M. A. Perazella, "Nephrology Fellowship Training in the 21st Century: Where Do We Stand?” Clinical Journal of the American Society of Nephrology, Vol. 5, No. 3, 2010, pp. 387-389. doi:10.2215/CJN.00070110

[10] J. S. Berns, “A Survey-Based Evaluation of Self-Perceived Competency after Nephrology Fellowship Training," Clinical Journal of the American Society of Nephrology, Vol. 5, No. 3, 2010, pp. 490-496. doi:10.2215/CJN.08461109
[11] W. Mitch and W. M. McClellan, "Patterns of Patient Care Reported by Nephrologists: Implications for Nephrology Training,” American Journal of Kidney Diseases, Vol. 32, No. 4, 1998, pp. 551-556. doi:10.1016/S0272-6386(98)70016-2

[12] R. Mehotra, P. Blake, N. Berman and K. Nolph, "An Analysis of Dialysis Training in the United States and Canada," American Journal of Kidney Diseases, Vol. 40, No. 1, 2002, pp. 152-160. doi:10.1053/ajkd.2002.33924

[13] E. Grapsa, "Is the Underutilzation of Peritoneal Dialysis in Relation to Hemodialysis as Renal Replacement Therapy, Justifiable Worldwide,” Hippkratia, Vol. 15, Suppl 1, 2011, pp. 13-15.

[14] P. G. Blake and F. O. Finkelstein, "Why Is the Proportion of Patients Doing Peritoneal Dialysis Declining in North America?” Peritoneal Dialysis International, Vol. 21, No. 2, 2001, pp. 107-114.

[15] L. Troidle, A. Kliger and F. Finkelstein, "Barriers to Utilzation of Chronic Peritoneal Dialysis in Network \#1, New England," Peritoneal Dialysis International, Vol. 26, 2006, pp. 452-457.

[16] D. Wuerth, S. Finkelstein, O. Schwetz, H. Carey, A. Kliger and F. Finkelstein, "Patients' Descriptions of Specific Factors Leading to Modality Selection of Chronic Peritoneal Dialysis or Hemodialysis,” Peritoneal Dialysis International, Vol. 22, No. 2, 2002, pp. 184-190.

[17] A. G. Stack, "Determinants of Modality Selection among Incident Dialysis Patients: Results from a National Study," Journal of the American Society of Nephrology, Vol. 13, No. 5, 2002, pp. 1279-1287.

[18] US Census Bureau, "Census Bureau Regions and Divisions with State FIPS Codes,” 2011. http:///www.census.gov/geo/www/us_regdiv.pdf

[19] A. R. Nissenson, R. Agarwal, M. Allon, A. K. Cheung, W. Clark, T. Depner, et al., "Improving Outcomes in CKD and ESRD Patients: Carrying the Torch from Training to Practice," Seminars in Dialysis, Vol. 17, No. 5, 2004, pp. 380-397. doi:10.1111/j.0894-0959.2004.17350.x

[20] M. G. Parker, "Nephrology Training in the 21st Century: Toward Outcomes-Based Education,” American Journal of Kidney Diseases, Vol. 56, No. 1, 2010, pp. 132-142.

[21] N. G. Kutner, R. Zhang, Y. Huang and H. Wasse, "Patient Awareness and Initiation of Peritoneal Dialysis," Archives of Internal Medicine, Vol. 171, No. 2, 2011, pp. 119-124. doi:10.1001/archinternmed.2010.361 